\title{
Viewpoint \\ Extreme growth factor signalling can promote oestrogen receptor- $\alpha$ loss: therapeutic implications in breast cancer
}

Julia MW Gee, Martin G Giles and Robert I Nicholson

Tenovus Centre for Cancer Research, Welsh School of Pharmacy, Cardiff University, CF10 3XF, Wales, UK

Corresponding author: JMW Gee, gee@cardiff.ac.uk

Published: 9 June 2004

Breast Cancer Res 2004, 6:162-163 (DOI 10.1186/bcr904)

(c) 2004 BioMed Central Ltd

\section{Introduction}

Most breast cancers overexpress the oestrogen receptor (ER)- $\alpha$, and the ER $\alpha+$ phenotype is relatively stable during endocrine treatment and on subsequent treatment failure. However, approximately $30 \%$ of tumours are $\mathrm{ER} \alpha-$ at diagnosis, while a proportion of tumours, which are initially $\mathrm{ER} \alpha+$, lack the receptor at the time of tamoxifen relapse in the adjuvant or metastatic setting. The mechanisms underlying de novo and acquired ER $\alpha$ negativity remain poorly-defined, although their elucidation is of obvious therapeutic interest since the ER $\alpha$ - phenotype is associated with endocrine resistance, aggressive tumour biology and poor prognosis. Somatic mutations in the ER $\alpha$ gene are quite rare and are therefore unlikely to explain the frequency of $E R \alpha$ negativity. Epigenetic mechanisms, notably $\mathrm{CpG}$ island methylation and histone deacetylation, may contribute by silencing $E R \alpha$ gene transcription in approximately $25 \%$ of de novo ER $\alpha$ - cancers [1]. Interestingly, ER $\alpha$ expression and function can be partially recovered in ER $\alpha$ - models using the DNA methyl transferase (DNMT) inhibitor aza-2-deoxycytidine, DNMT1 antisense, or the histone deacetylase inhibitor trichostatin [2]. However, there is also emerging evidence that sustained, exaggerated growth factor pathways [notably those hyperactivating extracellular signal-regulated kinases (ERK)1/2 mitogen activated protein kinase (MAPK)] may promote substantial decline, and even total loss, of ERo. A new article by Holloway and colleagues [3] sheds light on this mechanism of ER $\alpha$ negativity, revealing that exaggerated ERK1/2 MAPK signalling promotes ER $\alpha$ downregulation via its impact on cytoplasmic substrates that include the transcription factor nuclear factor kappa $B$ (NFKB).

\section{Hyperactivation of ERK1/2 MAPK promotes oestrogen receptor loss via cytoplasmic substrates including NFKB}

Growth factor pathways can enhance ER $\alpha$ phosphorylation, transcriptional activity and cell growth in the absence of ER $\alpha$ ligand. Paradoxically, a decline in ER $\alpha$ expression may also be a possible outcome when growth factor signalling is extreme, reminiscent of the ER $\alpha$ downregulation that occurs during chronic receptor activation by oestrogen [4]. Supportive evidence are drawn from stable transfection studies where growth factor signalling elements, notably those comprising the epidermal growth factor receptor (EGFR)/HER2 pathway, promote ER $\alpha$ loss when overexpressed in ER $\alpha+$ breast cancer cells. Oh and colleagues noted precipitous decreases in ER $\alpha$ mRNA and protein in MCF-7 cells transfected with constitutively active HER2, mitogen activated kinase kinase 1 (MEK1), Raf-1 kinase (Raf1) or ligand-activatable EGFR, all of which hyperactivate ERK1/2 MAPK [5]. They also noted a loss of oestrogenmediated gene expression and oestrogen response element (ERE) activity, and acquisition of endocrine resistance. Interestingly, the phenomenon was reversible, since abrogation of hyperactivated ERK1/2 MAPK restored ER $\alpha$ expression and activity. Extending these studies, Holloway and colleagues have now begun to decipher the mechanism of MAPK-mediated ER $\alpha$ loss in these various transfected models. Using dominant negative constructs, they show that hyperactivated ERK1/2 MAPK downregulate ER $\alpha$ via a common substrate. Use of an ERK2 deletion construct to prevent nuclear MAPK activity reveals this substrate is cytoplasmic. By examining potential MAPK substrates 
(again using appropriate dominant negatives), they demonstrate that activator protein-1 (AP-1) and $90 \mathrm{kDa}$ ribsosomal S6 kinase 1 (RSK1) are not responsible for the ER downregulation promoted by MAPK hyperactivation. However, there does appear to be some importance for $\mathrm{NF} \kappa \mathrm{B}$. This growth-promoting transcription factor can be cytoplasmically-activated (prior to its nuclear translocation) via MAPK-mediated induction of autocrine growth factors (e.g. heparin-binding EGF). Holloway and colleagues demonstrate gross elevation of NFKB activity in the various models exhibiting MAPK hyperactivation. This NFKB activity is inhibited by abrogating ERK1/2 MAPK signalling. Importantly, blockade of NFKB activity (e.g. using Parthenolide) restores ER $\alpha$ expression and activity in parallel, although interestingly there was only partial recovery indicating existence of additional cytoplasmic substrates.

\section{Conclusions}

These new data obtained by Holloway and colleagues in stable transfected cells are important in that they provide proof of principle that extreme growth factor signalling, resulting in ERK1/2 MAPK hyperactivation and recruitment of cytoplasmic substrates including $N F \kappa B$, is capable of promoting ER $\alpha$ loss. Further molecular detail of the receptor downregulation mechanism, determination of growth factor signalling thresholds required to instigate $\mathrm{ER} \alpha$ loss, and the impact of hyperactivation of additional signalling cascades (e.g. phosphatidylinositol 3' kinase [6]) is now required. Questions clearly remain regarding relevance to $\mathrm{ER} \alpha$ negativity de novo or acquired during therapy. Significant, however, is the inverse ER $\alpha / E G F R$ association in clinical disease and elevated ERK1/2 MAPK and NFKB signalling observed in ER $\alpha$ - cells $[7,8]$. Moreover, ER $\alpha$ transrepresses proinvasive genes and so growth factor-mediated $\mathrm{ER} \alpha$ loss may underlie poor prognosis in ER $\alpha$ negative disease [6]. Finally, modestly increased growth factor signalling activates $\mathrm{ER} \alpha$ in acquired tamoxifen resistance, explaining subsequent antihormone response; however, more extreme/prolonged signalling might promote $\mathrm{ER} \alpha$ negative endocrine insensitivity in some patients during sequential endocrine challenge [7].

While future studies are clearly required, the data from Holloway and colleagues do have exciting ramifications for possible therapeutic approaches in ER $\alpha$ - disease. Manipulation of growth factor pathways (in particular ERK1/2 MAPK and potentially NFKB signalling) with signal transduction inhibitors (STIs) might feasibly recover $\mathrm{ER} \alpha$ positivity in ER $\alpha$ - cells, hence restoring sensitivity to antioestrogen if used in combination. Importantly, the group demonstrate that in vitro pharmacological or dominant negative blockade of ERK1/2 MAPK signalling does re-instate physiological levels of ER $\alpha$ expression and function in their stable-transfected cells. Of course, we must await future experimental consolidation and appropriate clinical examination, but a compelling preliminary study demonstrates that reversion of ER $\alpha$ negativity and re-instatement of endocrine responsiveness occurs in a proportion of advanced HER2+ breast cancer patients using Herceptin to inhibit growth factor signalling [9]. Since this mechanism may only be applicable in tumours without epigenetic ER $\alpha$ silencing, combination therapy of STIs plus appropriate strategies to abrogate ER methylation/deacetylation could prove worthy of future exploration. However, DNMT1 can be growth factorregulated and so perhaps sustained increases in growth factor signalling ultimately culminate in $\mathrm{ER} \alpha$ promoter silencing. If so, STls might also prove effective in restoring $\mathrm{ER} \alpha$ where there is $\mathrm{ER} \alpha$ promoter hypermethylation. Intriguingly, pharmacological inhibition of Ras signalling does reverse gene methylation events in other cancer models via downregulating DNMT1 [10].

\section{Competing interests}

The authors are in receipt of research grants funded by AstraZeneca and Merck KGaA.

\section{References}

1. Parl FF: Multiple mechanisms of estrogen receptor gene repression contribute to ER-negative breast cancer. Pharmacogenomics J 2003, 3:251-253.

2. Yan L, Nass SJ, Smith D, Nelson WG, Herman JG, Davidson NE: Specific inhibition of DNMT1 by antisense oligonucleotides induces re-expression of estrogen receptor-alpha (ER) in ERnegative human breast cancer cell lines. Cancer Biol Ther 2003, 2:552-556.

3. Holloway JN, Murthy S, El-Ashry D: A cytoplasmic substrate of MAPK is responsible for ER $\alpha$ downregulation in breast cancer cells: the role of NFKB. Mol Endocrinol 2004, 18:1396-1410 [Epub 2004 Mar 31].

4. Stoica GE, Franke TF, Wellstein A, Morgan E, Czubayko F, List $H J$, Reiter R, Martin MB, Stoica A: Heregulin- $\beta 1$ regulates the estrogen receptor-alpha gene expression and activity via the ErbB2/PI 3-K/Akt pathway. Oncogene 2003, 10:2073-2087.

5. Oh AS, Lorant LA, Holloway JN, Miller DL, Kern FG, El-Ashry D: Hyperactivation of MAPK induces loss of ERalpha expression in breast cancer cells. Mol Endocrinol 2001, 15:1344-2359.

6. Bhat-Nakshatri P, Campbell RA, Patel NM, Newton TR, King AJ, Marshall MS, Ali S, Nakshatri $\mathrm{H}$ : Tumour necrosis factor and $\mathrm{PI3}$-kinase control oestrogen receptor alpha protein level and its transrepression function. $\mathrm{Br} J$ Cancer 2004, 90:853-859.

7. Nicholson RI, Hutcheson IR, Knowlden JM, Jones HE, Harper ME, Jordan N, Hiscox SE, Barrow D, Gee JM: Non-endocrine pathways and endocrine resistance: observations with antiestrogens and signal transduction inhibitors in combination. Clin Cancer Res 2004, 10:346S-354S.

8. Nakshatri H, Bhat-Nakshatri P, Martin DA, Goulet RJ, Jr., Sledge GW, Jr.: Constitutive activation of NF-kappaB during progression of breast cancer to hormone-independent growth. Mol Cell Biol 1997, 17:3629-3639.

9. Munzone E, Nole F, Renne G, Balduzzi A, Sanna G, Corsetto L, Goldhirsch A: Reverting estrogen receptor (ER) negative phenotype in advanced breast cancer patients over-expressing HER2 after treatment with trastuzumab plus chemotherapy. Proc Am Soc Clin Oncol 2003, 22:848 [Abstract 3409].

10. Alcock RA, Dey S, Chendil D, Inayat MS, Mohiuddin M, Hartman G, Chatfield LK, Gallicchio VS, Ahmed MM: Farnesyltransferase inhibitor (L-744,832) restores TGF-beta type II receptor expression and enhances radiation sensitivity in K-ras mutant pancreatic cancer cell line MIA PaCa-2. Oncogene 2002, 21: 7883-7890. 